\title{
The Role of Social Networks in the Organization of the Educational Process and Learning
}

\author{
https://doi.org/10.3991/ijim.v15i11.21545 \\ Viktor Shestak $(\varpi)$ \\ MGIMO University, Moscow, Russian Federation \\ viktor. shestak234@rambler.ru \\ Alena Gura \\ Kuban State Technological University, Krasnodar, Russian Federation \\ Uliana Borisova \\ North-Eastern Federal University, Yakutsk, Russian Federation \\ Daria Kozlovskaya \\ Russian State Social University, Moscow, Russian Federation
}

\begin{abstract}
The objectives of the study are to conduct a survey among students and teachers of Russian universities, which will determine their general attitude to the use of social networks in education; to identify the functions of social networks from the perspective of respondents; based on the findings of two stages of the research, to determine the social networks meaning in the learning processes. The question of the completeness and effectiveness of the use of social networks in classroom and distance learning is relevant in relation to individual countries and regions, since the full use of such social networks remains problematic. The study aims to fill this gap in relation to Russia. Students and teachers of four Russian universities (MGIMO University, Kuban State Technological University, North-Eastern Federal University, Russian State Social University) took part in the survey. The study involved 500 students (150 masters and 350 bachelors) aged 18-25 (248 women and 252 men) and 100 teachers aged 27-65 (the average age was 46.3). The results of the first part of the study showed that the teachers and students views on the social media applying in education is generally positive. Both groups of respondents noted the advantages of introducing social networks into the process of development of education and also stated their willingness to increase their use. When using social networks in education, students can fill in special forms to indicate social network accounts to be subsequently used. Also, the administration of group chats can be taken under the control of the university for the purpose of a more structured exchange of information/educational materials.
\end{abstract}

Keywords-Social networks in higher education; distance learning; social networks; social networks for schools 


\section{Introduction}

In the modern world, e-learning is an advanced tool that influents students strongly. It ensures personalized online education and can significantly stimulate self-motivation. Social networks have proved themselves as an important component of the global communication structure. Facebook, Google+, and Twitter and other networks bring people together through shared efforts. Social media are growing as users add friends and follow other groups, they interested in. Communities founded online with shared information exchange and messages can be developed based on school networks, employment networks, and other common interest groups. A user of modern social network can search for friends, share ideas and organize events by posting comments in public areas and using of special messages [1].

A significant part of the research literature is focused on the issue of the acceptability and effectiveness of the social media implementation in learning over the past 4 years. For this study, studies were selected that have a quantitative methodology and relate to the assessment of the social networks' usage as part of the learning process of online or mobile learning or the pedagogical process in general. A large body of practical and technological research related to specific methods of preparing learning management systems or massive online courses was mostly left out of consideration, since the work concerns the learning process as a whole.

Social media encourages participation and collective input. Bennett and McWhorter [2] studies the significance of the power of people in the age of the peer. Introducing the examples of YouTube and Amazon, researches emphasizes that the business models of most successful companies focused on online networking based on the use of the fruits of the activities of netizens. With the advancement of Web 2.0 instruments, new communication methods (Flickr, YouTube and Slideshare) are emerging; these are completely user-centered platforms rather than just a bank of information that can be accessed when needed. New mechanisms of cooperation and communication are being developed, including in the learning environment [3].

The people engagement in social media has increased dramatically for the last decade [4]. The latest review by We Are Social [5] demonstrated over 3 billion users of social media worldwide. This clearly reflects a change in personal relationships that results from an alternative form of communication, search for news and knowledges, and systematic activities related to the students' behavior [6].

Although these social information systems are mostly aimed at entertainment and leisure, there is important focus on the use of the instruments for learning and other occupational activities [3]. Social networks encourage teachers and students to work collaboratively to create socialized content. The education use of new media in allows students to connect with experts in the subjects they study [7].

The education system cannot remain unresponsive to the profound changes brought about by social media; on the contrary, it must try to adjust to the renewable of students' interests who are affected by this unusual phenomenon [8]. The learning style of modern students differs from the one before. Students have developed differing needs depending on the degree of participation in the educational process, which leads to higher 
autonomy, and the acquisition of new knowledge based on a large amount of information based on an extensive methodology and concentrated on the especially social results of educational process. Thus, social networks are perfect partners in the educational and methodological process. Despite the fact that they were not originally conceived for educational purposes, they have proven to be an excellent tool for teaching and learning innovative practices [7].

Recent research confirms that social media effected positively efficiency in many types of learning. There are pedagogical advantages associated with the social networks implementation for educational purposes in functions of communication and interactivity between teachers and disciples [9]. The positive effect of using social networks dough is associated with their implementation in well-organized learning systems based on "cloud" services and multichannel access to information, data exchange and interaction between students in collaboration [9-11].

Collaborative learning contributes to higher academic performance compared to individual learning. Scientists conclude that there are few educational innovations that can ensure the same outcome as technologically-supported collaborative learning. In the open-source culture, creativity becomes a shared experience. Online space sharing and peer-to-peer communication are a significant sphere of the daily lives of children, adolescents and young adults; therefore, they should foster user persistence and motivation to learn [12].

Collaborative teaching methods are most naturally implemented in a structured Massive open online course (MOOC) and knowledge management systems (LMS) with wide access to various types of teaching materials $[12,13]$. The interaction of students with each other is typically organized on the basis of already successfully operating social networking tools and built-in instant messengers and file downloads. Recent research shows that students are ready for a greater degree of integration and interaction, but predominantly even MOOC are used as shared file repositories, and not as integrated online learning systems with broad capabilities [10,11].

Some researchers are more critical of the use of social media for teaching as they believe that these technologies negatively affect student grades and academic achievement [14]. According to recent research, this is associated with the following variables: lack of student competence in social media; functional use of teachers; anticipated effort and mitigation.

The spread of the Internet, in particular Web 2.0 instruments, has led to the educational paradigm shift and transfer from vertical integrated structure focused on academics and assimilation of knowledge to a network organization. Web 2.0 including social networking, involves a various range of web technologies that give users ability to manipulate information and consume it. Typically, it includes social media websites, wikis, blogs, etc. The integrated use of these LMS tools requires the use and stimulation of the student's social activity, his openness, exchange of information and opinions, interest in a wide search for information [15-17]. Social networks can naturally serve to enhance the involvement of students accustomed to the digital environment in the process of education and simultaneously provide tools for the technical integration of learning and social services. Wikis, for example, best suited to create a collaborative 
environment for teaching and assisting fellow practitioners as they ensure quick feedback, observational learning and confident informational navigation [18]. In addition, students are encouraged to use similar tools to integrate blogs, bookmarks and other Web 2.0 elements to further their learning experience [13].

There are many studies on the teachers' and students' assessment of social media implementation in teaching process. However, as evidenced by the history of such studies, this assessment is ambiguous and varies depending on the location of the study. Changes in the digital ecosystem and social relations, the emergence of crises like the COVID-19 epidemic are changing this attitude. The objective of this study is to determine the actual attitude for Russia at the time of the study. This study will complement other similar ones to create a global vision and understanding of the further practical development of the implementation of mentioned media in classical classroom and online learning systems around the world.

According to Habibi et al. [8], students prefer to act on social media groups and forums than other instruments of online learning. So far, research on the use of social media in usage of learning has been mainly centered on the applying of one social network, such as Facebook [19] or YouTube [20].

In this regard, it was decided to conduct the study, the objectives of which are as follows:

- To survey students and teachers of Russian universities to determine their general attitude to the use of social networks in education;

- To identify the functions of social networks from the perspective of respondents;

- Based on the results of both stages of the study, to determine the role of social networks in the educational process.

The research is organized as follows: Introduction briefly outlines the relevance, reasons and objectives of the research, and provides an overview of the literature most closely related to the research topic over the past 5 years. Methods describe the research method and survey setting that was the basis for the study. The results describe the findings of the research and the teaching methods applied in the research process. The Discussion evaluates the results obtained in terms of existing research in the field.

\section{$2 \quad$ Method}

\subsection{Research design}

Based on the research objectives, an empirical study, which involved a survey of students and teachers of Russian universities, was conducted in order to collect information. There were two stages in the survey. At the first stage, the respondents were asked to choose one answer option while at the second stage they had to answer the questionnaire questions on their own. The selection of the research methodology was based on the fact that it would allow us to consider the problem from the perspective of both the recipients and providers of education. 


\subsection{Participants}

Students (bachelors and masters) of four Russian universities took part in the survey. A total of 500 students (150 masters and 350 bachelors) aged 18-25 were interviewed. There were 248 women and 252 men (Table 1).

Table 1. Students participating in the study

\begin{tabular}{|l|c|}
\hline \multicolumn{1}{|c|}{ Educational institution } & Number of students participating in the study \\
\hline MGIMO University & 140 \\
\hline Kuban State Technological University & 120 \\
\hline North-Eastern Federal University & 115 \\
\hline Russian State Social University & 125 \\
\hline
\end{tabular}

There also were 100 teachers aged 27-65 (the average age was 46.3) who took part in the survey (25 respondents from each educational institution). Thus, the total number of respondents was 600 people.

Based on the size of the general sample of the study, which includes all teachers and students of the Magister and Bachelor's degree of the universities participating in the study and taking into account the maximum representation of the studied feature in the sample, the possible statistical error of the sample does not exceed $p-3.21$. Thus, the sample is representative.

Also, the representativeness within certain groups of respondents significant for the research purposes (bachelor's and master's students separately, teachers, participants from each individual university) does not fall below $p=3.91$ and is also representative.

\subsection{The participant's selection criterion}

University teachers and students were invited to participate in the study to assess their attitude towards the use of social networks in education. Due to the fact that the future profession of the respondents does not play a decisive role in the study, the survey was conducted among the representatives of both technical and humanitarian fields in order to expand the scope of the research.

Also, this study does not focus on the issue of gender, age or social differences in attitudes towards the use of social networks in learning. These questions are left by the authors for further expansion of the study. Universities were selected from different geographic areas and from different prevailing ethnic backgrounds and environments within the Russian Federation in order to make the sample as representative as possible. Senior students were selected as the most interested in obtaining a profession and already sufficiently prepared during the academic course to be able to assess the quality of academic training and the application of various methods in it. 


\subsection{Research instruments}

The first stage of the study was a survey consisting of ten yes/no questions (Table 2).

For the survey, the classic 5-point Likert scale was used with values from "1" "completely disagree, no" to "5" - "I fully confirm, yes."

Table 2. Student and teacher survey

\begin{tabular}{|c|l|}
\hline No. & \multicolumn{1}{|c|}{ Question } \\
\hline 1 & Do you think that currently social networks can be used not only for entertainment? \\
\hline 2 & Do you agree that in the modern world social networks can become an educational tool? \\
\hline 3 & Are social networks used at your university? \\
\hline 4 & $\begin{array}{l}\text { Do you agree that the use of social networks can have a positive effect on motivation to study as it } \\
\text { reduces the formality of the educational process? }\end{array}$ \\
\hline 5 & $\begin{array}{l}\text { Do you agree that the use of social networks can negatively affect the educational process as it in- } \\
\text { cludes an element of "hobnobbing" between students and teachers? }\end{array}$ \\
\hline 6 & $\begin{array}{l}\text { Do you think that the introduction of social networks into the educational process will make it more } \\
\text { convenient? }\end{array}$ \\
\hline 7 & $\begin{array}{l}\text { Do you think that social networks in education should be used only for information sharing (for ex- } \\
\text { ample, groups on social networks which provide the timetable of classes, etc.)? }\end{array}$ \\
\hline 8 & Do you agree that a social network is a convenient way to distribute demonstration material? \\
\hline 9 & Do you think that the use of social networks allows you to obtain additional educational information? \\
\hline 10 & Would you like to use social networks more extensively in learning (teaching)? \\
\hline
\end{tabular}

The survey aimed to determine general attitudes towards social networks in education, as well as to find out if these were used in the universities considered. In addition, questions 4-6 are of particular importance as they allow us to assess the general attitude to the use of social networks in education, as well as to compare whether the opinions of students and teachers coincide. The survey will provide information on the most likely uses of social networks (questions 7-9) according to respondents.

The questionnaire was created on the basis of a study of typological close research and highlighting critical topics in relation to the use of social networks in learning $[4,7,9,12-14]$. To determine the content of the questions, a preliminary survey was conducted among all study participants with a request to write down the most significant problems in this area. The collected formulations were revised stylistically and substantively and summarized in a series of questions. Then this unified set of questions was again presented to the participants to determine the completeness of the content and coverage of the topic. Each of the participants had to make sure that all the problems that were significant to him fell into the wording of the questions. After all participants agreed on the final wording, this secondary follow-up survey was conducted two weeks later using the test-retest method. Thus, the validity of the test was confirmed by three methods: the consent of the respondents that the questionnaire in its entirety covers the significant problems of the object under study; verification by the retest test method and confirmed the expert validity based on the typological similarity of the content of the questionnaire to those used in other closely related case studies. The reliability of the test was verified by the test results used further in the study using Cronbach Alpha. 
The obtained value is $\alpha=0.761$, which can be considered a high enough value for the test to be applied in practice.

At the second stage of the study, the responses were not limited to specific answer options. Students and teachers were asked to independently propose options for the use of social networks in education. The survey was conducted remotely with the help of Google Forms. Each respondent taking part in the survey was sent a link with instructions and a response form.

\subsection{Research issues and restrictions}

One of the major research restrictions relates to the fact that the sample involved only students of higher educational institutions. This does not allow judging the attitude to and use of social networks in school and college education. That is why a number of problems and difficulties that were identified in the study, as well as recommendations for their solution, are applicable to this particular group of respondents. In addition, the survey was conducted exclusively among the representatives of Russian universities, which does not allow the assessment of the situation in other countries.

It should also be borne in mind that the list of questions from which the questionnaire was formed satisfies the problems recognized only by a limited number, albeit a representative sample, of students and teachers of a number of Russian universities. Expanding the number of participants to include representatives of other cultures and universities in other countries can make the results less valid. This issue requires further extensive research.

Further research can be more extensive and, for example, involve more countries in order to assess the situation worldwide. In addition, it is possible to identify the attitude to and degree of the use of social networks at other stages of education (at schools and colleges).

\subsection{Data analysis}

The STATISTICA system was used to analyse the first part of the survey. The software developed based on Microsoft Windows allows data visualization in the statistical analysis. The margin of error is $1 \%$, about 6 questionnaires were filled in incorrectly (some respondents did not answer all the questionnaire questions or chose more than one answer option).

As a result of the survey, descriptive statistics of the answers of students and teachers with an assessment of the problem under study were obtained. Then, by calculating the Pearson chi-square for the answers of each of the individual groups of significance to the study (bachelors, masters, teachers, representatives of individual universities, men or women), the researchers determined whether certain questions were more meaningful for a particular group? The task was to determine the degree of significance and characteristics of the prevailing attitude towards the use of social networks in teaching among different groups of respondents. 
All responses received through Google Forms were considered and analysed. The most common answer options were highlighted and grouped into categories; each category was explained in detail to ensure better understanding.

\section{7 $\quad$ Ethical Issues}

Participation in the study was voluntary. Before the beginning of the first stage of the study, the invitations were sent to all university departments and the students were informed about the possibility of participating in the study. In addition, the study was conducted anonymously. To ensure anonymity, the surveys submitted in Google Forms did not include any fields for entering personal data. After receiving the link to the survey, the respondents filled in and submitted forms, which were automatically accepted by the service.

\section{Results}

For convenience, when analysing the first part of the survey, only positive answers were considered. To better assess attitudes towards the use of social networks in education from the perspective of students and teachers, a comparative chart was used (Figure 1).

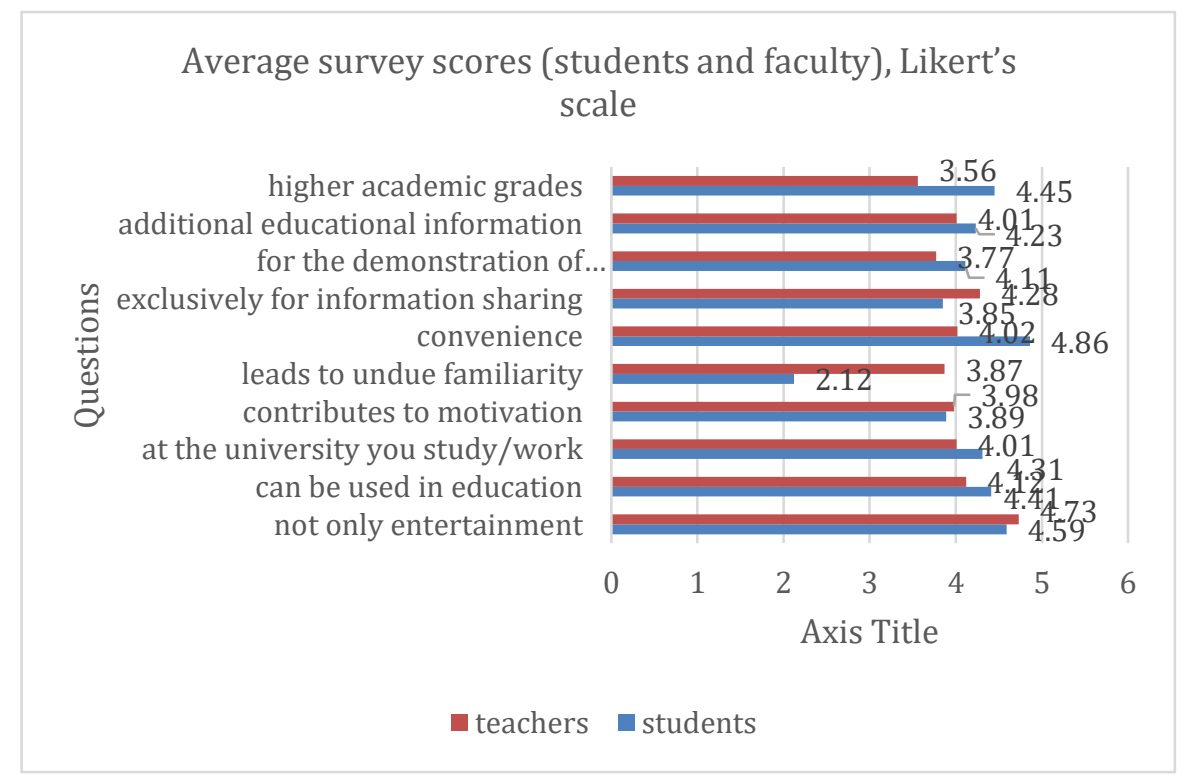

Fig. 1. The attitude of students and teachers towards the use of social networks in education (average scores)

The results of the study showed that both groups of respondents almost unanimously agree that social networks can be used for both entertainment and educational purposes. 
This indicator can be considered as positive as it may indicate that the introduction of social networks into education will not be opposed by students and, more importantly, teachers. However, despite this fact, most teachers did not agree that social networks can positively influence student motivation, and more than $50 \%$ of them concluded that the use of these resources can make communication between teachers and students excessively informal. The result may be explained by the age of respondents; however, this cannot be confirmed as the survey was conducted anonymously.

As for the use of social networks in education, both groups of respondents noted certain advantages. Thus, teachers find the opportunity to inform students through social networks as most important while students highly appreciate the opportunity to receive demonstration materials through social networks. In general, the results of the first stage of the study can be considered positive, which is confirmed by the responses to the last question - the majority of respondents from both groups expressed their desire to extend the social networks usage.

At the second stage of the study, students and teachers were asked to independently determine the uses of social networks in education. At this stage of the study, the answers of both groups of respondents were combined and analysed. The answers were grouped by functionality, and if possible, specific social networks were highlighted for each function. The groups were arranged randomly without any gradation.

Pearson's chi-squared analysis did not demonstrate a statistically significant deviation of the mean values for the groups from the mean critical value for the entire analyzed sample as a whole. There were only four exceptions. For the group of students as a whole, and not for the groups of individual universities, for questions 1 and 6, chisquare values were obtained with $\mathrm{p}=0.31$ and $\mathrm{p}=0.34$; for a group of teachers, $\mathrm{p}=$ 0.29 and $p=0.34$ were obtained for questions 5 and 6 . Accordingly, the attitude of these groups of respondents to the problems formulated in these questions has a statistically significant prevalence over others, the average estimates obtained in the surveys for these categories are statistically more significant against the general background.

Students" scores on social media use other than entertainment (4.45) are statistically more significant than lower scores from teachers. Students expect a wider and more active inclusion of social media in teaching methods and educational process. Also statistically significant is a higher assessment of students that the applying of social media will make the learning process more convenient (4.86 for students versus 4.02 for teachers), which is generally supported by teachers, but much less. Students are more actively living in a digital environment, while for teachers it causes some precautions. Teachers (3.87) are more afraid of the negative impact of social networks, while students are not inclined to think so (2.12).

\subsection{Organizational provision of information}

One of the indisputable conveniences of social networks is the ability to quickly and massively communicate information (note: in this case, this refers exclusively to organizational issues, for example, when it is necessary to inform about the cancellation of the lesson and the deadline for the delivery of completed assignments). Both groups of respondents noted this opportunity very often. Among the resources that allow such 
interaction, Vkontakte was most popular. According to the respondents, this social network is the most convenient platform for sending messages as it allows the creation of multi-user conversations, which can be entered, for example, by all students of a certain group and their teachers. In addition, it allows instant messaging, which is important in case of informing about something urgent. The disadvantage of this communication method is that not all participants in the process can have a profile on this social network. Another communication tool mentioned was email.

\subsection{Distribution of educational materials}

This function overlaps with the previous paragraph; however, it was decided to place it into a separate category. Distribution of educational and demonstration materials can also become one of the functions of social networks. Among the resources, Vkontakte and email were also the most common; the first one was noted as more convenient due to its fewer file size limits and the ability to create groups to upload and view materials without downloading them (for example, videos).

\subsection{Getting more educational information}

According to respondents, YouTube is the most frequently used resource for additional learning. In their opinion, the platform provides the most convenient format for presenting information, as well as the opportunity to combine videos by knowledge categories by creating playlists. In addition, some respondents noted the possibility of obtaining additional knowledge from Vkontakte articles.

\subsection{Demonstration materials}

This refers to both distribution and demonstration directly at the lesson. YouTube can be used for demonstration, as well as services such as SlideShare.

\subsection{Organization of educational activities}

This category was most often mentioned in the responses of students who reported that social networking makes group organization much more convenient. They noted the creation of group chats to share assignments, distribute responsibilities in group projects, as well as topics of reports, as the most important options for the use of social networks in education.

\subsection{Distance learning}

Modern realities are increasingly promoting distance education. The respondents noted that social networks have become a convenient tool for distance learning as they can ensure the learning experience that is close to studying in the classroom. Among social networks, they especially highlighted Skype and Zoom, which allow organizing 
group video calls, as well as social networks that support live broadcasts (for example, Vkontakte, YouTube and Instagram) and allow the teacher to conduct a lecture online and receive questions from students in the comment format.

Thus, having analyzed both parts of the survey, we can conclude that social networks occupy a prominent place in the educational process as they have important organizational functions. Given this fact, the management of educational institutions should pay more attention to the social media implementation in the educational pipeline.

For example, when students are admitted to university, they could fill in special forms to indicate their social media profiles to be subsequently used. However, it should be noted that such an initiative may be negatively accepted by students as not every person wants to share their personal profiles, as well as the information they contain. In addition, not all students may have a profile on the required network.

The administration of group chats can also be taken under control (for example, assigned to the group president). This will make the process of transferring information and materials more well-tuned and formal.

In addition, if there is a need to use video communication services, students can be given logins and passwords registered by the university, which will guarantee that all students have the opportunity to connect to the video conference. This will also eliminate difficulties related to the identification of each student profile as when registering for personal needs, students can choose an abstract username and remove any personal data.

If there is a desire of the university management and there are available funds, a social network of the educational institution can also be created (if it has not been created yet), where each student who enters the university will be registered. The resource can be developed taking into account the needs of a particular university. However, unlike the use of available social networks, this practice requires much more resources as it will be necessary to involve specialists (developers, designers), as well as to spend money on its maintenance (server payment, website maintenance, etc.). In case the educational institution has distance learning portals, it is possible to revise their functionality and add the functions of social networks, where applicable. For example, the expansion of the system of private messages, which will be based on the principle of social networks allowing users to attach various media files, as well as uniting students and teachers in text conferences.

\section{Discussion}

As social networks have penetrated our lives, research on their use in the educational process is being carried out around the world. Thus, McCarroll and Curran [21] argue that the potential benefits of social media in education are numerous and varied. This position is supported by all the participants in our study. Primarily this is due to the fact that their effectiveness in communication can already be observed in the big number of people who use these networks for everyday communication. Student collaboration underlies a constructivist educating environment, and social media sites provide a platform for building collaborative learning communities. In the presented study, the views 
of both students and teachers, and the subgroups of those studied within these groups completely coincide in this aspect. By their nature, social networks are focused on relationship and facilitate the exchange of experience [3].

However, Deng et al. [22] argue that when using social media, teachers should create a rich learning environment that fosters individual and group activities through multiple communication and collaboration channels. This approach will encourage students to take part in learning processes more actively and interact with educators. These are not new concepts; they have been anchored in best education practices for many years. The assessment of social media as a communication tool interaction with peers and with the teacher, as well as the transfer of information and teaching materials, does not raise doubts among the respondents. This is also in line with the estimates obtained by scientists from other countries [11,16,23,24].

Especially important is the assessment of developing countries, in which the formation of the digital environment still remains or is at a lower level of suffering than in developed countries [3]. A study on the use of social media in higher education took place for example in Malaysia. The object of the research was to examine their impact on the quality of teaching and learning. Thus, five factors have been found to be important determinants of the benefits of teaching and learning based on the use of social media, namely academic reasons, convenience, social media availability, ease of use, and e-learning perception [25].

The academic reasons are consistent with other studies that have shown that students and teachers are taking a position on the application of social networks in learning $[20,26]$. As noted in our study, social media ensure more quality communication and a alliance sensation between students and teachers, which in general can have a positive effect on motivation to learn. Manasijević et al. [28] write about teachers implemented social media in education found better scores in tests and writing fluency and language. In addition, social media relationships between students and teachers can develop their collaboration and interaction, which will generally develop the educational environment.

Face-to-face the teacher - student interaction establish trust relationships and therefore creates a high productive and efficient learning environment. To put it in a nutshell, social media can promote the information exchange between students and teachers that relates to formal goals of education policy [28].

The researchers note that the factors of usability and ease of use are also associated with a number of new media, including Facebook, Twitter and YouTube [28]. Similarly, they highlight YouTube as it allows users to easily and quickly download and search for academic content. On the other hand, Twitter makes it easy to share minimal size comments makes feedback instant, and therefore fits the social context of surroundings for the learning and teaching [2]. Hortigüela-Alcalá et al. [29] also argue that the Instagram and Twitter both learning usage has a significant positive impact raising motivation of students and increasing engagement in the educational process, as well as their academic performance. Another research [30] has shown that the learning usage of social media promotes both non-formal learning and student engagement in their personal academic achievements, which are determining factors in promoting lifelong learning. 
Habibi et al. [8] discuss the approach approving the core of the successful engagement of social media in the educational process is the rational and controlled use of social networks by the teacher; there should always be intelligible rules of intervention and a focus on the major topics to be learned. Thus, they note that this process must be controlled by the teacher in order to bring positive results. Our study identified significant concerns on the part of teachers about the negative impact of social networks, which may hinder the development of their use. Some works indicate that a possible way out of the situation is the development of training programs and the sharing of experience in the pedagogically effective development of the use of social networks $[19,20]$.

As for the information aspect, Jacquemin et al. [31] have found that teachers should realize and consider the fact that information will arrive from multiple sources in this case (when using social networks): teachers, students and other members of the educational community with Internet access. Therefore, feedback generated information have been filtered necessarily. Moreover, in order to have capacity to give rich feedback to peers, students ought to gain more experience in learning. This experience might increase the teacher - student interaction by opportunities of the network social media process [15], as well as during the preparation and review of assignments.

The research similar to that of Bruine de Bruin et al. [32] found that age is the key factor in the social media usage in context of high education practices, primarily when it concentrates on their regular use that maintains the relationship among users. For the older generation, it may be more difficult to accept and put into practice computerization in education. These results are partly supported by our findings indicating a more cautious attitude towards social media among teachers of the (older) generation.

A study by De Meo et al. [16] demonstrates the reasons for the social media consuming, especially Facebook; namely, the effective communication between people and the ease of sharing knowledge. Another study by Altinay [23] describes methods to help learners and encourage them to work together to achieve common learning outcomes by understanding the concept of collaborative learning. They believe that the most effective method is face-to-face collaborative learning in small groups.

On the other hand, another research demonstrates that social media tools and multiple sites can sufficiently reduce the students' performance. There was a survey in this study to confirm the fact of getting higher grades by students who reduce their time on the Internet [24]. Thus, spending more time on social media may result in lower student grades. In addition, some students do not properly use a system, such as e-learning, which also leads to poor academic performance [17].

Thus, the world experience confirms that the education implementation of social networks is not only possible, but also capable of bringing positive results. However, when introducing this practice, it is necessary to take into account the nuances of each educational institution and potential users. 


\section{Conclusion}

Based on the study and the reviewed literature, we can conclude that new media networks capable be actively used in the process of education development. To identify possible ways of using social networks in higher education, a two-stage study was organized; it involved students and teachers of four Russian universities. The first stage of the study was making a questionnaire aimed at the assessment of the general attitude of respondents to the social network's educational usage. The results of the survey showed that the teachers and students position towards the social networks learning engagement in education is generally positive. The study showed that the main aspects of attitudes towards teaching engagement of social media in, both online and in classroom teaching, for teachers and students are the same. Students' scores on social media use other than entertainment (4.45 on 5 points Likert's scale) are more significant than lower scores from teachers. Students have a higher assessment of that the social media usage will make the processes of learning more convenient (4.86 for students versus 4.02 for teachers). Students are actively living in a digital environment, while for teachers it causes some precautions. Teachers (3.87) are afraid of the negative impact of social networks due learning, while students are not inclined to think so (2.12).

Both groups of respondents noted the advantages of introducing social networks into the educational process (the ability to quickly exchange information and demonstration material, ease of use), and also expressed their readiness to use them more often. However, the teachers expressed concern that the use of social networks could lead to excessive informality in the communication between the teacher and the student, which could negatively affect the learning process; in addition, many of them also questioned the possibility of motivating students by the instrumentality of social media in the learning process. In contrast, students found social media to be a motivating factor. Unlike other studies, this study examines aspects of attitudes towards social networks that critically differentiate the groups studied - students and teachers. The results obtained can be practically used to eliminate difficulties in the introduction of training programs using social networks.

At the second stage of the research, the respondents were asked to independently determine the goals to be achieved by social networks usage. The causes of the using of this type media indicated by the respondents were grouped into the following categories: organizational provision of information (for example, through the creation of group chats to report changes in the schedule and other information not related to the educational materials); obtaining additional educational information (watching educational videos, reading articles and scientific papers); distribution of learning and demonstration materials (group chats can also be used for this purpose). In addition, the possibility of sharing demonstration materials at the lesson was noted; organization of educational activities (in particular within study groups). On social networks, students can share assignments, distribute responsibilities in group projects, as well as topics of reports, etc.; they can study remotely through the use of various services for video conferences and live broadcasts allowing viewers (in this case students) to ask questions in the comments in real time. 
Students can be asked to fill in special forms to indicate their social media profiles to be subsequently used in the learning process. The administration of group chats can be taken under the control of the university for the purpose of a more structured exchange of information/educational materials. Also, in the case of using video communication services, students may be given accounts registered by the university, which will guarantee that all students have the opportunity to connect to the video conference and eliminate difficulties related to the identification of each student profile as it will definitely contain personal data. In addition, the management of educational institutions can create their own internal social network as a separate site or based on the available distance learning platform.

Other Russian and foreign universities can later take the results of the study as a basis for their own research on the role of social networks in learning processes. In addition, similar research can take place in schools and colleges.

\section{References}

[1] Nikolopoulou, K. (2018). Mobile technologies and early childhood education. In International Conference on Technology and Innovation in Learning, Teaching and Education. Springer, Cham, pp. 444-457. https://doi.org/10.1007/978-3-030-20954-4_33

[2] Bennett, E.E., McWhorter, R.R. (2020). Digital technologies for teaching and learning. In 2020 Handbook on adult and continuing education, Stylus, pp. 177-186.

[3] Boholano, H. (2017). Smart social networking: 21st century teaching and learning skills. Research in Pedagogy, 7(1): 21-29. https://doi.org/10.17810/2015.45

[4] Sadowski, C., Pediaditis, M., Townsend, R. (2017). University students' perceptions of social networking sites (SNSs) in their educational experiences at a regional Australian university. Australasian Journal of Educational Technology, 33: 77-90. https://doi.org/ $\underline{10.14742 / a j e t .2927}$

[5] Hootsuite (2018). Digital year book. Retrieved from https://www.slideshare.net/wearesocial/2018-digital-yearbook-86862930

[6] Bond, R.M., Bushman, B.J. (2017). The contagious spread of violence among US adolescents through social networks. American journal of public health, 107(2): 288-294. https://doi.org/10.2105/AJPH.2016.303550

[7] Manca, S., Ranieri, M. (2017). Networked scholarship and motivations for social media use in scholarly communication. The International Review of Research in Open and Distributed Learning, 18: 123-138. https://doi.org/10.19173/irrodl.v18i2.2859

[8] Habibi, A., Mukminin, A., Riyanto, Y., Prasojo, L.D., Sulistiyo, U., Sofwan, M., Saudagar, F. (2018). Building an online community: Student teachers' perceptions on the advantages of using social networking services in a teacher education program. Turkish Online Journal of Distance Education, 19: 46-61. https://doi.org/10.17718/tojde.382663

[9] García-Álvarez, M.T., Novo-Corti, I., Varela-Candamio, L. (2018). The effects of social networks on the assessment of virtual learning environments: A study for social sciences degrees. Telematics and Informatics, 35(4): 1005-1017. https://doi.org/10.1016/j.tele.2017 .09 .013

[10] Papadakis, S., Kalogiannakis, M., Sifaki, E., Vidakis, N. (2017). Access moodle using smart mobile phones. A case study in a Greek University. In Interactivity, game creation, design, learning, and innovation. Springer, Cham, pp. 376-385. https://doi.org/10.1007/978-3-31976908-0_36 
[11] Papadakis, S., Kalogiannakis, M., Sifaki, E., Vidakis, N. (2018). Evaluating moodle use via smart mobile phones. A case study in a Greek university. EAI Endorsed Transactions on Creative Technologies, 5(16): 1. https://doi.org/10.4108/eai.10-4-2018.156382

[12] Kompen, R.T., Edirisingha, P., Canaleta, X., Alsina, M., Monguet, J.M. (2019). Personal learning Environments based on Web 2.0 services in higher education. Telematics and informatics, 38: 194-206. https://doi.org/10.1016/j.tele.2018.10.003

[13] Bugawa, A.M., Mirzal, A. (2018). The impact of Web 2.0 technologies on the learning experience of students in higher education: A review. International Journal of Web-Based Learning and Teaching Technologies, 13(3): 1-17. https://doi.org/10.4018/IJWLTT. 2018070101

[14] Rostaminezhad, M.A., Porshafei, H., Ahamdi, A.A. (2019). Can effective study approaches mediate the negative effect of social networking on academic performance?. Education and Information Technologies, 24(1): 205-217. https://doi.org/10.1007/s10639-018-9770-y

[15] Tang, Y., Hew, K.F. (2017). Using Twitter for education: Beneficial or simply a waste of time?. Computers \& education, 106: 97-118. https://doi.org/10.1016/j.compedu.2016. $\underline{12.004}$

[16] De Meo, P., Messina, F., Rosaci, D., Sarné, G.M. (2017). Combining trust and skills evaluation to form e-Learning classes in online social networks. Information Sciences, 405: $107-$ 122. https://doi.org/10.1016/j.ins.2017.04.002

[17] Almaiah, M.A., Alyoussef, I.Y. (2019). Analysis of the effect of course design, course content support, course assessment and instructor characteristics on the actual use of E-learning system. Ieee Access, 7: 171907-171922. https://doi.org/10.1109/ACCESS.2019.2956349

[18] Medero, G.S., Albaladejo, G.P. (2020). The use of a wiki to boost open and collaborative learning in a Spanish university. Knowledge Management \& E-Learning: An International Journal, 12(1): 1-17. https://doi.org/10.34105/j.kmel.2020.12.001

[19] Park, E., Song, H.D., Hong, A.J. (2018). The use of social networking services for classroom engagement? The effects of Facebook usage and the moderating role of user motivation. Active Learning in Higher Education. https://doi.org/10.1177/1469787418809227

[20] Jia, S. (2019). Literature Review of YouTube in Teaching Activities. In Pacific Asia Conference on Information Systems. PACIS, pp. 228.

[21] McCarroll, N., Curran, K. (2013). Social networking in education. International Journal of Innovation in the Digital Economy, 4(1): 1-15. https://doi.org/10.4018/jide.2013010101

[22] Deng, L., Li, S.C., Lu, J. (2018). Supporting collaborative group projects with Web 2.0 tools: A holistic approach. Innovations in Education and Teaching International, 55(6): 724-734. https://doi.org/10.1080/14703297.2017.1321494

[23] Altınay, Z. (2017). Evaluating peer learning and assessment in online collaborative learning environments. Behaviour \& Information Technology, 36(3): 312-320. https://doi.org/10. 1080/0144929X.2016.1232752

[24] Samad, S., Nilashi, M., Ibrahim, O. (2019). The impact of social networking sites on students' social wellbeing and academic performance. Education and Information Technologies, 24(3): 2081-2094. https://doi.org/10.1007/s10639-019-09867-6

[25] Zachos, G., Paraskevopoulou-Kollia, E.A., Anagnostopoulos, I. (2018). Social media use in higher education: A review. Education Sciences, 8(4): 194. https://doi.org/10.3390/ educsci8040194

[26] Lantz-Andersson, A., Lundin, M., Selwyn, N. (2018). Twenty years of online teacher communities: A systematic review of formally-organized and informally-developed professional learning groups. Teaching and Teacher Education, 75: 302-315. https://doi.org/10.1016/ j.tate.2018.07.008 
[27] Galvin, S., Greenhow, C. (2020). Educational networking: A novel discipline for improved K-12 learning based on social networks. In Educational Networking. Springer, Cham, pp. 341. https://doi.org/10.1007/978-3-030-29973-6_1

[28] Manasijević, D., Živković, D., Arsić, S., Milošević, I. (2016). Exploring students’ purposes of usage and educational usage of Facebook. Computers in Human Behavior, 60: 441-450. https://doi.org/10.1016/j.chb.2016.02.087

[29] Hortigüela-Alcalá, D., Sánchez-Santamaría, J., Pérez-Pueyo, Á., Abella-García, V. (2019). Social networks to promote motivation and learning in higher education from the students' perspective. Innovations in Education and Teaching International, 56(4): 412-422. https://doi.org/10.1080/14703297.2019.1579665

[30] Abella, V., Delgado, V. (2015). Aprender a usar twitter y usar twitter para aprender. Profesorado: Revista de Currículum y Formación del Profesorado, 19(1): 364-378.

[31] Jacquemin, S.J., Smelser, L.K., Bernot, M.J. (2014). Twitter in the higher education classroom: A student and faculty assessment of use and perception. Journal of College Science Teaching, 43(6): 22-27. https://doi.org/10.2505/4/jcst14_043_06_22

[32] Bruine de Bruin, W., Parker, A.M., Strough, J. (2020). Age differences in reported social networks and well-being. Psychology and aging, 35(2): 159. https://doi.org/10.1037/ pag0000415

\section{$7 \quad$ Authors}

Shestak Viktor Anatolyevich is a Doctor of Juridical Science, Professor of the Department of Criminal Law, Criminal Procedure and Criminology, MGIMO University, Moscow, Russian Federation.

Gura Alena Yurevna is a PhD of Philosophical Sciences, Associate Professor of the Department of History, Philosophy and Psychology, Kuban State Technological University, Krasnodar, Russian Federation.

Borisova Uliana Semenovna is a Doctor of Sociological Sciences, Professor of the Department of HR and Sociology, North-Eastern Federal University, Yakutsk, Russian Federation.

Kozlovskaya Daria Igorevna is a bachelor of the Department of Social Work, Russian State Social University, Moscow, Russian Federation.

Article submitted 2021-01-27. Resubmitted 2021-03-18. Final acceptance 2021-03-18. Final version published as submitted by the authors. 